\title{
SKIN-GRAFT IN A CASE OF TOTAL SYMBLEPHARON*
}

\author{
BY
}

\author{
R. K. KESWANI
}

Department of Plastic and Reconstructive Surgery

DHANWANT SINGH

Department of Ophthalmology

AND

R. L. MANCHANDA

Department of Plastic and Reconstructive Surgery

Government Medical College and Rajendra Hospital, Patiala, Punjab, India

MANAGEMENT of conjunctival ulceration in the acute stages following chemical injuries and certain infectious diseases is one of the most difficult problems confronting ophthalmic surgeons. This is challenging, more so when the internal structures of the eye-ball are not affected. The cornea may be fairly normal in many such cases. Severe damage to the conjunctiva, unless properly treated, will lead to scarring, adhesions, and blindness. However, once the conjunctiva is destroyed, partial restoration of vision can be obtained by lining the conjunctival sac with some of the available replacement tissue, i.e., oral mucosa, homografts of conjunctiva, prepuce, labia minora, split skin-grafts, autografts of conjunctiva, amniotic sac, etc. (Duke-Elder, 1954; Stallard, 1950; El-Rifaiy, 1962; Reeh and Mason, 1961; and El Gammal, 1961).

This paper presents our experience in a case of total bilateral symblepharon, which developed following an infectious fever, probably smallpox.

\section{Case Report}

The patient was first admitted to Rajendra Hospital, Patiala, in August, 1963, for treatment of loss of vision in both eyes. He had developed smallpox about seven months previously and at the same time he also developed diffuse ulceration in both conjunctival sacs, resulting in total symblepharon in both eyes, involving both upper and lower eyelids.

At the time of admission he had narrow fixed palpebral fissures in both eyes, measuring about 4-5 mm. in width. In both eyes five-sixths of the cornea was fixed under the upper eyelids. Visible portions of cornea and palpebral fissures were covered by whitish membrane, which was dry, dull, and opaque (Figs $1 \mathrm{~B}$ and 2).

The first operation was done on the left side. The eyelids were released and the cornea freed; both fornices were deepened; a full-thickness mucous membrane graft was obtained from the lower lip and stitched in place. However, most of the graft did not take and symblepharon recurred in both eyelids. The cornea remained free under the upper eyelid and part of the upper eyelid became lined with mucous membrane. The lower fornix was $1.0 \mathrm{~mm}$. deep. Vision was limited to perception and projection of light only.

* Received for publication April 20, 1964. 


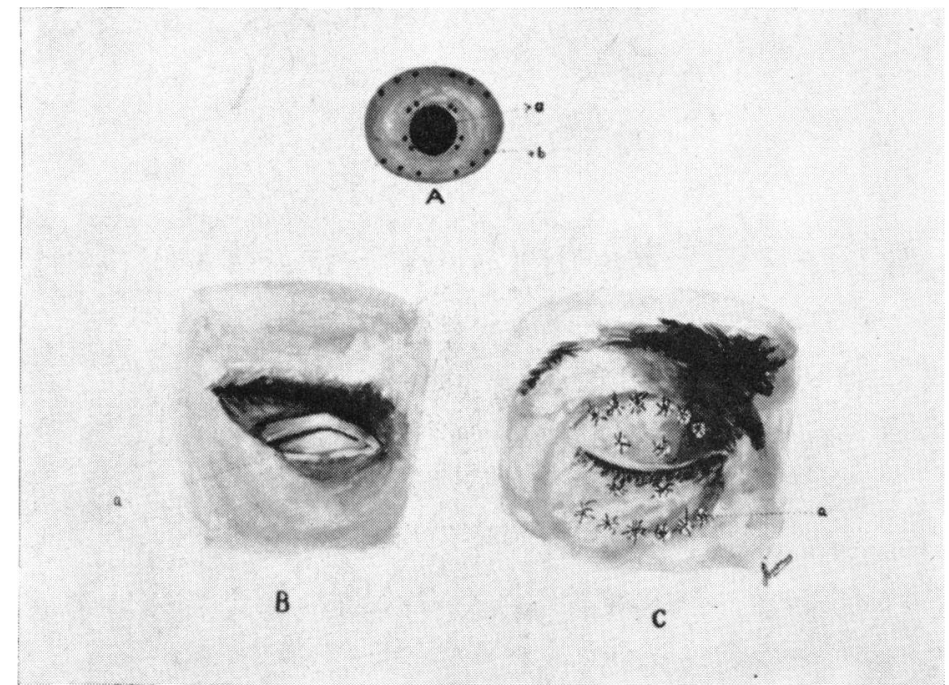

FIG. 1.-Diagrammatic sketch showing A, Acrylic prosthesis with (a) central hole for the cornea and (b) multiple small holes at the margins of the prosthesis and around the hole for the cornea for passage of stabilizing sutures. B, Pre-operative condition of the patient's right eye. C, Multiple sutures in the eyelids at the end of the operation fixing the graft and prosthesis in place. Sutures are tied over small pieces of petroleum jelly gauze.

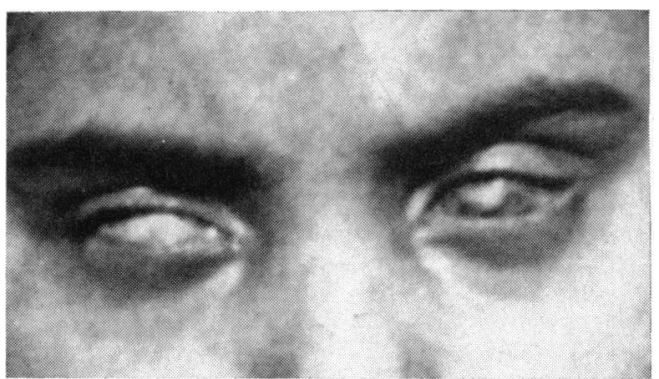

FIG. 2.-Pre-operative photograph of the patient showing adherent eyelids and narrow palpebral fissure in the right eye; palpebral fissure in the left eye is slightly larger as a result of previous operation.

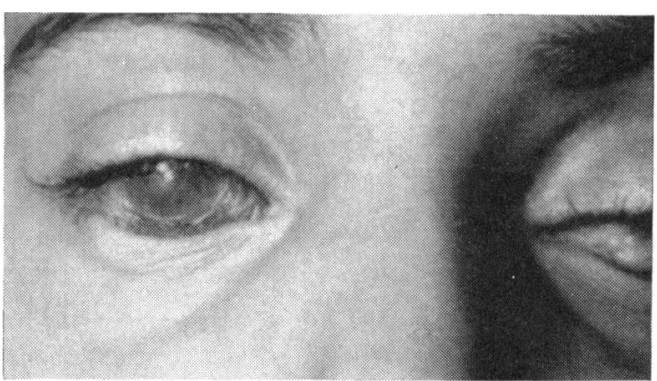

FIG. 3.-Post-operative photograph of the right eye showing glistening cornea and skin-graft below the cornea.

The second operation was performed in November, 1963, on the right eye. The upper and lower eyelids were freed and the fibrous membrane excised from over the cornea; both fornices were deepened. Cornea could now be pulled down but it always tended to rise up under the upper eyelid. The whitish membrane lining the fissure was left attached to the lower limbus. A thin, slightly curved, acrylic prosthesis was prepared before the operation (Fig. 1A), which measured $31 \mathrm{~mm} . \times 22 \mathrm{~mm}$., i.e., the approximate dimensions of the obliterated conjunctival sac. An opening $12.0 \mathrm{~mm}$. in diameter was made in the centre of the plate for the cornea. Small holes were made at the upper and lower margins of the plate for passing stabilizing sutures through the upper and lower fornices. Small holes were also made at the upper and lower margins of the central opening for the cornea. Sutures passed through the eyelids, prosthesis, and tissues around the cornea stabilized the cornea under the central hole of the acrylic prosthesis.

A full-thickness mucous membrane graft was taken from the right buccal mucosa. However, because of poor access to the donor site the graft obtained was too thick and it contracted a great deal. An attempt to thin and stretch it was unsuccessful and it was decided to use a thin split skin-graft from a non-hairy area of the abdomen. This was done with the help of a miniature 
roller dermatome. The epidermal graft was peeled off the dermatome and attached to the prosthesis with the help of dermatome glue. A hole for the cornea was cut in the graft on the bulbar side. Graft and prosthesis were now fixed in the newly created cavity with the help of sutures (Fig. 1C) passed through the fornices and margins of the eyelids. The eye was bandaged with an elastic bandage exerting mild pressure. The dressing was opened on the seventh day and the sutures and prosthesis removed. Atropine and Terracortril ointment were used until healing was complete.

The graft healed well on the bulbar part of the sac and lower eyelid, resulting in a deep lower fornix (Fig. 3). Slight ulceration occurred in the graft in the upper lid resulting in a shallow upper fornix and limitation of movements. The cornea became more hazy during the post-operative period, but treatment with cortisone and atropine has decreased the opacity, and details of the iris and pupil can be seen. Epithelium has grown over the cornea at the upper limbus and a few corneal opacities remain. A few downy hairs can be seen with the help of a loupe. No irritation from sebaceous secretion has been noted five months after the operation. Vision at present is finger counting $1.0 \mathrm{~m}$.

\section{Discussion}

No case of bilateral and total symblepharon with its treatment has been reported in the recent English literature. When the entire conjunctival tissue is lost in both eyes the restoration of vision has to depend on finding a suitable substitute of graft material. Whereas many such have been described in the literature the authors used the most easily accessible autografts. Mucous membrane grafts have been described as a fairly good replacement tissue in such cases. One of us (D.S.) tried this in the first operation, using a wide full-thickness graft from the lower lip, the classic donor site. However, owing to thickness of the graft and fixation without prosthesis, only a small part of the graft took. The second operation was performed after making a proper prosthesis, as described above. However, a wide mucous membrane graft measuring $31 \mathrm{~mm} . \times 44 \mathrm{~mm}$. was needed for the purpose. This unfortunately could not be obtained because of lack of good exposure. A smaller piece that could be removed contracted a great deal and appeared too thick. We believe that this difficulty can probably be obviated by using Castroviejo's (1959) cheek retractors and a miniature electric dermatome. Under the circumstances, it was decided to use a Thiersch graft from a non-hairy part of the body. This was easily done and the results have been quite encouraging, at least in as far as it has restored some vision to the patient.

After five months of follow-up, certain observations have been made:

(1) Growth of downy hair: This was not expected as the graft used was quite thin. No evidence of irritation from these fine hairs has been noticed. However, no sebaceous secretion has been noted so far.

(2) Growth of skin over the upper part of the limbus: This has naturally reduced the visual field of the patient. Skin has not grown across the lower part of the limbus, but as described above, remnants of scarred conjunctiva were left attached in this area.

(3) Dryness of the conjunctiva: We expected dryness of the conjunctival sac, because of lack of tear secretion, but with the use of ointments the eye has remained fairly clear and glistening and the cornea has shown continued improvement. Consideration was given to transferring the parotid duct to the new conjunctival 
sac, but as this operation is not without hazard and discomfort to the patient (Kudoyarov and Vorontsova, 1961; Paul, 1960; and Farina, Attadia, Carvalho, and Baroudi, 1960) it has been postponed until its necessity becomes absolute. Besides, because of the growth of downy hair it may first be necessary to replace the palpebral skin-grafts with mucous membrane and then do a keratoplasty before transplantation of the duct.

(4) Until now the vision has steadily improved and the patient is able to move around by himself in the house.

At present we are still following the behaviour of the skin-graft in the right eye; we are also contemplating releasing the adhesions in the left eye and making a new conjunctival sac with the help of skin-grafts.

\section{Summary}

A case of total bilateral symblepharon is described. Whereas the use of skingrafting in the conjunctival sac has not been reported in recent years, in this case it was used with a fair degree of success. The technique and the post-operative care have been fully detailed.

We would like to thank Dr. Prem Chandra, Medical Superintendent, Rajendra Hospital, and Professor of Ophthalmology, Government Medical College, Patiala, for access to hospital records and advice in the writing of this paper. We also very much appreciate the time and labour spent by Dr. Chawla, Professor of Dentistry, Government Medical College, Patiala, and Mr. Phillips, maxillo-facial technician, who made the special acrylic eye prosthesis.

\section{REFERENCES}

Castroviejo, R. (1959). Plast. reconstr. Surg., 24, 1.

Duke-Elder, S. (1954). "Text-book of Ophthalmology," vol. 6, p. 6617. Kimpton, London.

El Gammal, Y. (1961). Bull. ophthal. Soc. Egypt, 54, 23.

El-RIFAIY, A. (1962). Ibid., 55, 411.

Farina, R., Attadia, E. R., De Carvalho, C. A., and Baroudi, R. (1960). Plast. reconstr. Surg., $26,410$. Kudoyarov, G. H., and Vorontsova, Z. I. (1961). Oftal. Zh., No. 6, p. $345 . \quad$ (Ophthal. Lit. (Lond.), 15, p. 330 , no. 1805.)

Paul, S. D. (1960). Proc. All-India ophthal. Soc., 19, 93.

ReEh, M. J., and Mason, M. S. (1961). Highlights Ophthal. (U.S. ed.), 4, $242 . \quad$ (Ophthal. Lit. (Lond.), 15, p. 643 , no. 3572 .)

Stallard, H. B. (1950). "Eye Surgery”, 2nd ed., p. 219. John Wright, Bristol. 